\title{
DOENÇA DE TAY-SACHS EM CRIANÇA DE RAÇA NEGRA
}

\author{
SÉrgio Rosemberg * \\ ANTÔNIO B. LEFÈVRE **
}

A idiotia amaurótica infantil precoce ou doença de Tay-Sachs é entidade familiar, de transmissão autossômica recessiva de penetrância completa, devida a um êrro inato do metabolismo dos gangliosidios. Primitivamente admitida como doença de incidência exclusiva em populações judaicas (asquenasi), a doença de Tay-Sachs tem sido descrita em diferentes grupos étnicos (judeus safardi, caucasianos, amarelos, latinos, árabes) ${ }^{5,15}$. Até o presente, foram descritos apenas quatro casos da doença de Tay-Sachs em indivíduos da raça negra ${ }^{4,8}$. Ford $^{9}$ afirma ter encontrado caso semelhante em criança negra, não nos tendo sido possivel localizar a publicação integral desta observação.

O objetivo dêste trabalho é o de acrescentar um quinto caso, cuja publicação se justifica pela raridade e pela possível contribuição para um futuro estudo genético e demográfico desta doença.

\section{O B S E R V A C}

E.P.R., sexo masculino, negro, com 20 meses de idade, internado em 231-1-1969 (Registro Geral 885924) por apresentar regressão do desenvolvimento psicomotor e crises convulsivas desde o $6 . .^{\circ}$ mês de vida. Antecedentes e anamnése - A gravidez foi perturbada por toxemia nas semanas finais. O parto foi demorado, a termo, em apresentação cefálica. As condições neonatais foram boas, o chôro imediato. Pêso ao nascer: $3.250 \mathrm{~g}$. O desenvolvimento psicomotor decorreu sem anormalidades nos seis primeiros meses: a criança sustentou a cabeça aos três meses e, aos seis, já sentava sem apôio. A mãe refere "bronquites" frequientes neste periodo. Por volta dos seis meses, a criança começou a apresentar "repuxamentos" dos membros inferiores, freqüentes e diários, e se "assustava" muito aos estímulos auditivos, ao mesmo tempo em que foi perdendo a vivacidade, deixando de apanhar os objetos. Progressivamente, tôdas as aquisiçōes do desenvolvimento psicomotor foram sendo perdidas. Aos 14 meses começou a apresentar crises convulsivas generalizadas. Com 16 meses, a criança não mais acompanhava os objetos com os olhos, permanecendo prostrada e completamente desligada do meio. Antecendentes familiais - o propósito é o último de uma série de seis irmãos, frutos de uma união de pais não consanguíneos, provenientes de cidades distantes entre si, situadas no Estado de Minas Gerais. Dos seis filhos, quatro estão vivos e livres de doença. O quinto faleceu com a idade de três anos, após uma doença cuja evolução clínica teria sido idêntica, segundo a mãe, à apresentada pelo nosso paciente. Não há outros casos semelhantes no restante da

Clinica Neurológica, Departamento de Neuropsiquiatria, Faculdade de Medicina, Universidade de São Paulo: * Médico adido; ** Professor de Neuropediatria. 
familia. Exame físico - Paciente hipotrófico, emagrecido, com panículo adiposo escasso, desidratado, mucosas descoradas. A ausculta pulmonar, discretos, roncos disseminados. Fígado e baço não palpáveis. Exame neurológico - Paciente macrocéfalo (Fig. 1), completamente desligado do meio, sem qualquer forma de contacto, ape-

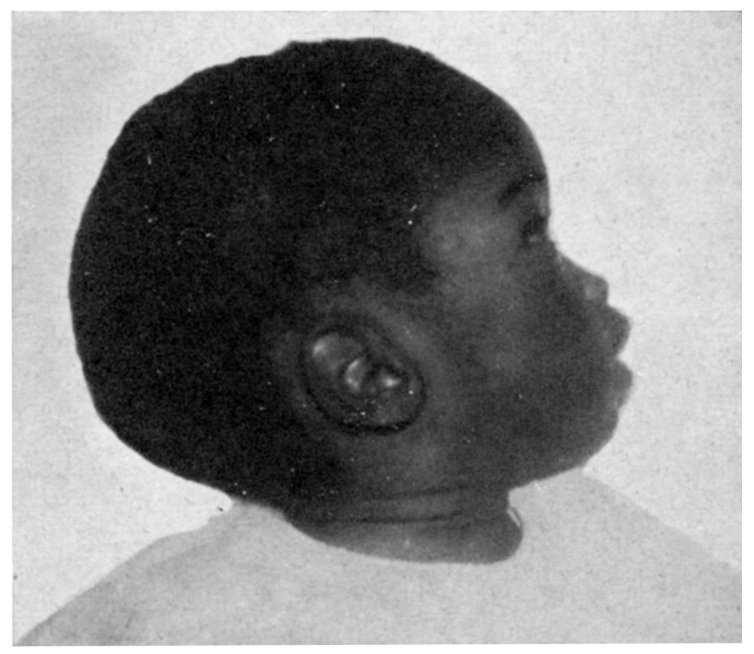

Fig. 1 - Caso E.P.R. Fotografia do paciente poucas semanas antes da morte. Notar o aspecto macrocefálico.

nas esboçando chôro quando manipulado. Movimentação expontânea pobre, reagindo globalmente aos estímulos dolorosos. Hipertonia global, espástica, com exaltação dos reflexos profundos. Sinais de libertação piramidal: clono dos pés, sinais de Rossolimo e Babinski presentes. Abalos clônicos generalizados, intensos e rápidos a qualquer tipo de estimulo: táctil, sonoro, luminoso. Fundoscopia: em ambos os olhos atrofia das papilas e, na região macular, mancha arredondada, vermelho-escura, quase negra, cercada de halo mais claro (Fig. 2)* Exames complementares Os seguintes exames laboratoriais de rotina se mostraram normais: glicemia, calcemia, uréia, creatinina sérica, creatina e creatinina urinárias, fosfatase alcalina, fosforemia, proteinograma sérico, urina tipo 1 e fezes. A taxa de transaminase glutâmico-oxalacética no sôro foi de 109 U. Frankl. A transaminase glutámico-pirúvica foi normal. Eletrencefalograma - Um EEG feito em 10 de janeiro mostrou espiculas e ondas agudas difusas, de projeção principal em áreas posteriores de ambos os hemisférios. Um segundo e um terceiro EEG, realizados com um mês de intervalo, mostraram sinais de sofrimento cerebral difuso (ondas contínuas de elevado potencial a 2-3 c/s.). O exame de rotina e a eletroforese do liquido cefalorraqueano resultaram normais. Mielograma normal, sendo negativa a pesquisa de linfócitos vacuolizados no sangue circulante. o exame radiológico não revelou alterações ósseas específicas, havendo apenas osteoporose difusa do tipo de desuso. A encefalografia gasosa, realizada dez dias após a internação, se mostrou normal, não tendo sido evidenciados sinais de atrofia cerebral.

* Os autores agredecem ao Dr. A. Tupinambá, da Clínica Oftalmológica da Santa Casa de Misericórdia de São Paulo, pela fotografia do fundo de ôlho. 


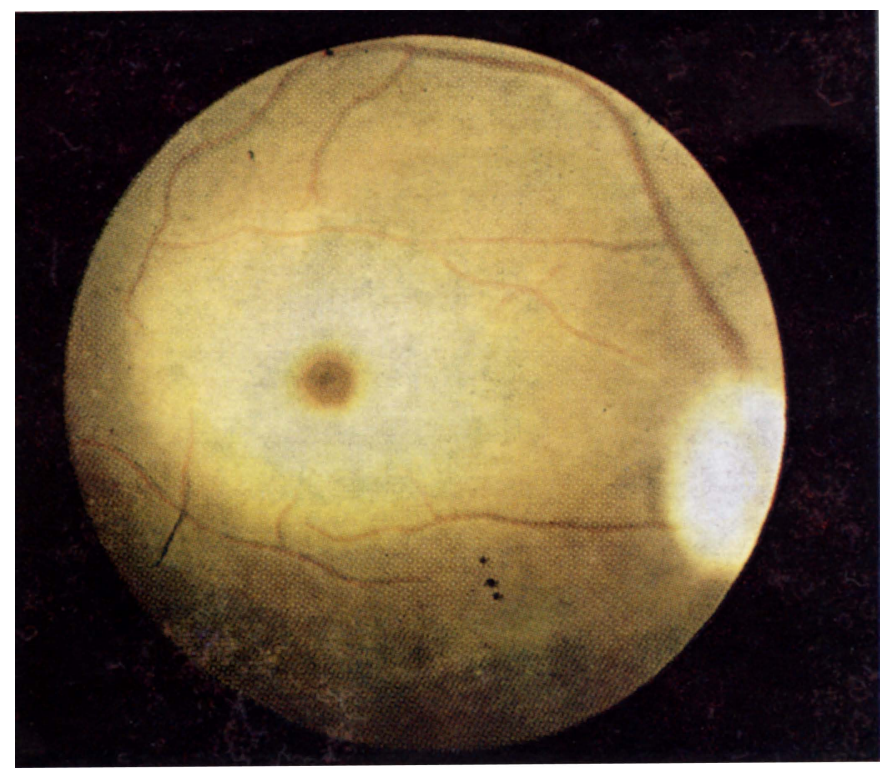

Fig. 2 - Caso E.P.R. Mancha macular típica da doença de Tay-Sachs.

Evolução - Durante todo o periodo de internação, o paciente permaneceu no estado vegetativo. As mioclonias foram diminuindo em freqüência e intensidade e, nas semanas finais, haviam desaparecido totalmente. Os reflexos profundos, de exaltados tornaram-se hipoativos para depois se abolirem, enquanto a espasticidade cedeu, dando lugar a hipotonia generalizada. Após quatro meses e meio de internação, durante os quais foram administrados cuidados gerais e medicação anticonvulsivantc, o paciente veio a falecer, em conseqüência a processo broncopneumônico, em 9-6-1969.

Anatomia patológica * - Macroscòpicamente, cérebro aumentado em seu volume, atingindo o pêso de $1.850 \mathrm{~g}$. Microscòpicamente, foi assinalađa diminuição da espessura do córtex cerebral, com preservação da citoarquitectonia. Diminuição difusa do número de neurônios que apresentavam aspectos variađos. Algumas vêzes apresentavam-se aumentados de volume com o peri-carion mostrando áreas claras em diversas localizações; notadamente em posição periférica, junto à membrana celular, deixando áreas de citoplasma junto ao cariolema em que o colorido é fortemente basofílico. O constituinte citoplasmático é finamente reticulado e, outras vêzes, era formado por pequenos grânulos fracamente basófilos. Não raramente os denditros apicais neuronais achavam-se grandemente alargados apresentando, em seu interior, as áreas claras com as mesmas características já descritas (Fig. 3). Estas alterações morfológicas estendiam-se, raras vêzes, até ramos de divisão secundária. Em outras ocasiôes, os neurônios encontravam-se diminuidos de volume; o peri-carion mostrava-se uniforme, fracamente eosinófilo, não se encontrando estruturações internas.

* Os autores agradecem aos Drs. C. C. Mattosinho-França e J. Guidugli do Serviço de Anatomia Patológica do Hospital dos Servidores Públicos do Estado de São Paulo, pelas fotomicrografias e pelo exame anátomo-patológico. 

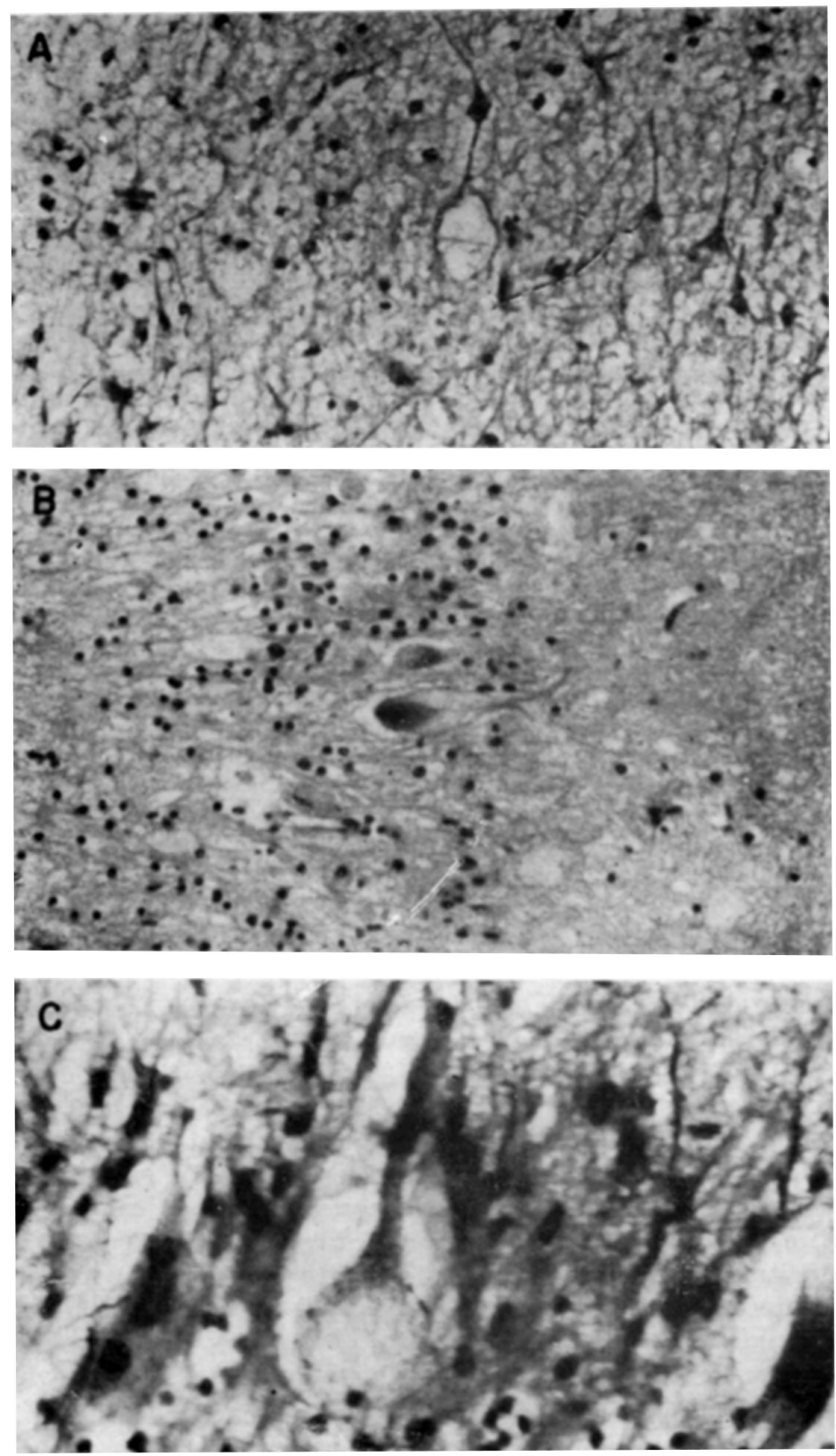

Fig. 3 - Caso E.P.R. em A, córtex cerebral mostrando grande alargamento de um dendrito apical neuronal (IV variante de Ortega, $155 x$ ); em $B$, córtex cerebelar mostrando grande diminuição dos neurônios moleculares e, no centro, uma célula de Purkinje com aspecto balonizado (H.E., $155 \mathrm{x}$ ); em C, célula de Purkinje com aspecto balonizado e grandes áreas claras no citoplasma finamente reticular (IV variante de Ortega, $400 x$ ). 
Seus núcleos, que ocupavam posição central, eram diminuídos de volume, com cromatina sob a forma de finos grânulos, raramente evidenciando-se a presença de nucléolos. Difusamente, tanto na substância cinzenta quanto na branca, os astrocitos estavam aumentados de número e seu citoplasma era eosinófilo e uniforme. Raramente dois dêles dispunham-se lado a lado. Células da oligodendróglia apresentavam citoplasma aumentado de volume, claro, opticamente vazio e núcleos de disposição central. Células da micróglia mostravam o citoplasma evidente, claro, òpticamente vazio. Estas células dispunham-se difusamente em meio ao parénquima, estando muitas vêzes presentes nos espaços perivasculares. $O$ neurópilo apresentava pequenas áreas claras, òpticamente varias, difusamente distribuidas.

Os cortes histológicos do cerebelo mostravam desaparecimento quase total dos neurônios da camada molecular. As células de Purkinje apresentavam-se grandemente diminuídas em número, notando-se no citoplasma grandes áreas claras, semelhantes às descritas anteriormente (Fig. 3). Muitas vêzes, os dendritos destas céIulas encontravam-se grandemente aumentados em seu volume. Os grânulos cerebelares encontravam-se igualmente diminuidos em seu número. Por outro lado, as células de Bergman encontravam-se numèricamente aumentadas, dispondo-se em áreas focais múltiplas, como em paliçada, junto às células de Purkinje restantes. As células da micróglia e da oligodendróglia, assim como a substância branca cerebelar, mostravam aspectos semelhantes aos já descritos. Corando os cortes histológicos pela técnica do ácido per-iódico-Schiff, verificou-se que os neurnios e as células da micróglia mostravam em seu interior grande número de pequenos grânulos fortemente corados. Entretanto, as técnicas de Sudan IV e Scarlach $\mathbf{R}$ mostraram-se negativas.

O fígado não mostrou alterações histológicas notáveis e o baço apresentou discreta hiperplasia retículo-endotelial.

\section{COMENTARIOS}

O trabalho de Aronson e col. ${ }^{4}$ foi o primeiro a demonstrar que o padrão clínico, anatômico e bioquímico da doença de Tay-Sachs é o mesmo quando se consideram populações judias em comparação com as não judias.

Aronson e col. ${ }^{1}$ e Kanof e col. ${ }^{11}$ estipularam, para efeito de estudo, três fases na evolução da moléstia, que, seguramente, foram observadas em nosso paciente: a) na primeira (0-14 meses), ocorrem hiperacusia, deterioração psicomotora progressiva e degeneração macular; b) na segunda (14-24 meses), ocorrem convulsões, persiste a hiperacusia, instala-se a atrofia muscular por desuso, e há queda progressiva em existência vegetativa; c) na terceira (24 meses em diante) a criança permanece imóvel, não reagindo aos estímulos, e apresenta atrofia pronunciada, hipotonia, arreflexia e macrocefalia. Infelizmente, em nosso caso, o perimetro craniano não foi medido no início da internação, mas nas fases finais podia-se notar evidente macrocefalia. O perimetro craniano, anotado cêrca de dez dias antes do óbito, foi de $52,5 \mathrm{~cm}$, francamente superior ao valor normal para a idade $(49 \mathrm{~cm})$.

$\mathrm{O}$ aspecto fundoscópico fundamentou o diagnóstico clínico. Se a mancha macular não apresentava a coloração característica descrita por Tay, sua forma, tamanho e situação eram as mesmas. A coloração vermelha escura, quase negra, nos parece semelhante à do caso 2 de Duke e Clark ${ }^{8}$. Esta mancha macular é devida à degeneração das células ganglionares da região, o que desnuda a camada pigmentar subjacente ${ }^{7}$. Esta camada, nos individuos da raça negra, pode assumir tons bastante escuros, côr de chocolate ${ }^{19}$, fato que explicaria porque ,em tais casos, a clássica mancha "ver- 
melho-cereja" poderia se mostrar com tal coloração. Cabe notar, no entanto, que em um dos casos de Aronson e col. ${ }^{4}$ a mancha macular era de coloração vermelho-cereja.

A taxa de transaminase glutâmico-oxalacética mostrou-se muito aumentada, conforme o esperado nesta entidade, mas o teor da transaminase glutâmico-pirúvica permaneceu normal, possivelmente refletindo êste fato as flutuações normais destas enzimas na fase da doença em que foram pesquisadas ${ }^{6}$.

Infelizmente não estamos, em nosso meio, habilitados a dosar a frutose-1-fosfato aldolase (F-1-PA), ausente nos pacientes com esta doença bem como nos indivíduos heterozigotos. Êste é, segundo Aronson e col. ${ }^{3}$, o meio bioquímico mais seguro de se chegar com certeza ao diagnóstico desta entidade e o único teste pelo qual pode-se detectar os portadores do gene anormal.

Nas fases iniciais da doença, o pneumencefalograma costuma revelar sinais de atrofia cortical, os quais comumente desaparecem nas fases mais adiantadas, possivelmente devido ao espessamento do tecido cerebral pelo acúmulo da substância de depósito ${ }^{2}$. Muito possìvelmente foi o que ocorreu em nosso caso no qual o exame pneumencefalográfico resultou normal.

Três eletrencefalogramas realizados com um mês de intervalo mostraram um padrão evolutivo caracterizado pela passagem de sinais da série comicial para um tipo de sofrimento cerebral difuso. Schneck ${ }^{16}$ notou que, após os dois anos, a alta voltagem e as pontas e polipontas verificadas anteriormente acabam por desaparecer. Provàvelmente, nossos achados poderiam vir a se superpor aos de Schneck se a evolução tivesse sido um pouco mais longa, pois, se o último traçado ainda mostrava um elevado potencial, os elementos comiciais já haviam desaparecido.

Geralmente, na doença de Tay-Sachs, a pesquisa de linfócitos vacuolizados no sangue circulante ou de células anormais na medula óssea é negativa, como ocorreu em nosso caso. Alguns autôres, como Spiegel-Adolf e col. ${ }^{17}$, referem ter encontrado pequena porcentagem de linfócitos com vacúolos no sangue circulante de pacientes com a doença de Tay-Sachs e em alguns de seus parentes. A percentagem destas células tenderia a aumentar com a progressão da doença.

Os aspectos anátomo-patológicos assinalados no caso aqui registrado, caracterizados notadamente por rarefação neuronal difusa, pelo encontro de imagens sugestivas de sobrecarga dos neurônios, que muitas vêzes assumem forma balonizada, bem como pelo alargamento dos dendritos apicais neuronais, condiz com o quadro usualmente descrito na doença de Tay-Sachs.

Os estudos genéticos mostraram que a doença de Tay-Sachs obedece ao modo de transmissão autossômico recessivo com dominância completa. A freqüência dos genes mutantes* é muito alta nas populações judias e seu número varia de 0,011 a 0,018 , conforme o autor considerado ${ }^{5,13}, 15$. Kozinn

* A freqüência do gene mutante numa dada população é a raiz quadrada da relação n.9 de doentes $/$ n. 9 total de nascimentos. 
e col. ${ }^{13}$ e Myrianthopoulos ${ }^{15}$, fazendo êsses cálculos em populaçōes não judias, chegaram a cifras bem menores, respectivamente, 0,0015 e 0,0013. O fato de que a freqüência do gene anormal ser tão elevado nos judeus, a ponto de 85 a $90 \%$ dos casos descritos ocorrerem neste grupo étnico, não encontrou ainda explicação satisfatória ${ }^{15},{ }^{17}$. Slome e Ktenidès, citados por Aronson e $\operatorname{Volk}^{6}$, mostraram que quanto menor a freqüência de um gene mutante em determinada população, maior deverá ser a taxa de consangünidade entre os pais dos indivíduos comprometidos, e vice-versa. Assim, a taxa de consangüinidade nos casos descritos em judeus foi de 18,9\%, ao passo que êste número se elevou a $50 \%$ nos casos ocorridos em outros grupos étnicos ${ }^{5}$. Dos oito casos descritos em países asiáticos, seis dos pacientes eram produtos de uniōes consagüineas, o que leva à expectativa de uma freqüência do gene da ordem de 0,0002 , ou seja, 1 caso para 25 milhões de nascimentos ${ }^{6}$. Dos cinco casos descritos na raça negra, em três dos pacientes não havia consangüinidade, em um êste dado não é fornecido e, um caso, o paciente era o produto de relação incestuosa entre pai e filha.

Avançar um cálculo genético, mesmo incompleto, com base em número tão pequeno de dados levaria a êrros grosseiros. Em nosso meio não existem estimativas seguras quanto ao número de nascimentos de crianças da raça negra (a estimativa da pureza da raça negra levaria a outro sério problema) e, seguramente, se outros casos semelhantes ao nosso existem, o diagnóstico passou desapercebido. Assim, é impossível a aplicação da fórmula de Hardig-Weinberg para o cálculo da freqüência do gene mutante em uma dada população.

Por outro lado, o fato de apenas um dos cinco casos publicados ser o produto de pais consangüíneos não deixa de causar certa surpresa, considerando-se que a freqüência do gene mutante para a doença em questão na raça negra deve ser extremamente baixa. Deve-se esperar que um número maior de casos venha a ser publicado para se obter uma estimativa mais segura concernente às implicações genéticas atinentes à incidência da doença de Tay-Sachs em indivíduos da raça negra.

$O$ advento de novas técnicas de pesquisa e, sobretudo, as recentes aquisições no domínio da bioquímica, tornaram precários os diagnósticos das assim chamadas doenças dos êrros inatos do metabolismo assentados em base puramente clínica e anatômica. O enorme desdobramento de entidades tidas como unívocas e autônomas tornaria sua enumeração enfadonha. No que concerne às neurolipidoses, recentemente foi isolada, com base na identificação da substância de depósito, uma nova entidade que, clínica e anatômicamente, poderia ser confundida com a doença de Tay-Sachs ou com a de Hurler ${ }^{10,14}$. A doença de Tay-Sachs interessa o metabolismo de determinado tipo de gangliosido $\left(\mathrm{G}_{\mathrm{M} 2}\right)$ e, modernamente, se propōe o nome gangliosidose a $\mathrm{G}_{\mathrm{M} 2}$ para a designação desta entidade ${ }^{18}$.

Infelizmente, em nosso meio, não estamos preparados para levar a cabo tais tipos de investigação. Entretanto, acreditamos que difìcilmente nosso caso poderia ser confundido com outra entidade. Do ponto de vista clínico, laboratorial e anatômico, nossos achados são congruentes com os casos clássicos descritos na literatura. 


\section{R E S U M O}

E relatado um caso de doença de Tay-Sachs em criança da raça negra. $O$ encontro desta entidade em individuos não judeus é bastante raro, sendo êste o quinto caso descrito em criança negra. Os autores estudam alguns aspectos genéticos, chegando à conclusão de que o cálculo da freqüência do gene mutante é impossivel devido ao pequeno número de casos e ao fato de que não há estimativas seguras quanto à taxa de nascimento de indivíduos negros na população, Em que pese o fato de o diagnóstico se assentar em bases puramente clínicas e anatômicas, prescindindo os autores de exames bioquímicos específicos, os dados aprcseitados são congruentes com os casos clássicos descritos na literatura.

\section{S U M M A R Y}

Tay-Sachs disease in a Negro child.

A case of Tay-Sachs diseases in a Negro child is reported. The occurrence of this disease in non-Jewish individuals is very rare and this is the fifth case of a Negro-child reported in the litterature. Some genetical aspects are studied and the authors conclude that the frequency calculation of the mutant gene is impossible due to the small number of cases and to the fact that there is reliable information regarding the rate of birth of Negro individuals in the general population. The diagnosis was based on ophtalmological and clinical data. No specific biochemical tests were performed but the data obtained are congruent with other cases reported in the litterature.

\section{R E F E R E N C I S}

1. ARONSON. S. M.; ARONSON, B. E. \& VOLK B. W. - A genetic profile of amaurotic family indiocy. Amer. J. Dis. Child. 98:50, 1959.

2. ARONSON, S. M.; LEWITAN. A.; RABINER, A. M.; EPSTEIN, N. \& VOLK, B. W. - The megalencephalic phase of infantile amaurotic familial idiocy. Arch. Neurol. Psychiat. 79:151, 1958.

3. ARONSON, S. M.; PERLE, G; SEIFER, A. \& VOLK, B. W. - The biochemical identification of the carrier state in Tay-Sachs disease. Proc. Soc. Exper. Biol. Med. 3:664, 1962

4. ARONSON, S. M.; VALSAMIS, M. P. \& VOLK B. W. - Infantlle amaurotic family idiocy: occurrence, genetic considerations and pathophysiology in the non-jewish infant. Pediatrics 26:229, 1960.

5. ARONSON, S. M. \& VOLK. B. W. - Genetic and demographic considerations concerning Tay-Sachs disease. In Stanley M. Aronson \& Bruno W. Volk: Cerebral Sphingolipidoses. Academic Press, New York, 1962, p. 375.

6. ARONSON, S. M. \& VOLK, B. W. -The nervous system sphingolipidoses. In Charles H. Carter: Medical Aspects of Mental Retardation. Charles C. Thomas, Springfield, 1965 . p. 684.

7. COOGAN, D. C. - Neurology of the Visual System. Charles C. Thomas, Springfield, 1966, p. 92.

8. DUKE, J. R. \& CLARK, D. B. - Infantile amaurotic familial idiocy (Tay-Sachs disease) in the Negro race. Amer. J. Ophtal. 53:800, 1962.

9. FORD, F. R. - Diseases of the Nervous System in Infancy, Childhood and Adolescente. Charles C. Thomas, Springfield, 1966, p. 728 .

10. GONATAS, N. K. \& GONATAS, J. - Ultrastructural and biochemical observations on a case of systemic late infantile lipidosis and its relationship to Tay-Sachs disease and gargoylism. J. Neuropath. Exp. Neurol. 24:318, 1965.

11. KANOF, A.; ARONSON, S. M. \& VOLK, B. W. - Clinical progression of amaurotic family idiocy. Amer. J. Dis. Child. 97:656, 1959. 
12. KNUDSON Jr., A. G. \& KAPLAN, W. D. - Genetics of the sphingolipidoses. In Stanley M. Aronson \& Bruno W. Volk: Cerebral Sphingolipidoses. Academic Press, New York, 1962 , p. 395.

13. KOZINN, P. J.; WIENE, H. \& COHEN, P. - Infantile amaurotic family idiocy. J. Pediat. 51:581, 1957.

14. LANDING, B. H.; SILVERMAN, F. N.; CRAIG, J. M.; JACOBY, M. D.; LAKEY, M. E. \& CHADWICK, D. L. - Familial neurovisceral lipidosis. Amer. J. Dis. Child. 108:503, 1964.

15. MYRIANTHOPOULOS, N. C. - Some epidemiologic and genetic aspects of Tay-Sachs disease. In Stanley M. Aronson \& Bruno W. Volk: Cerebral Sph ngolipidoses. Academic Press, New York, 1962, p. 359.

-16. SCHNECK, L. - The early electroencephalographic and seizure characteristics of Tay-Sachs' disease. Acta neurol. scand. 41:163, 1965.

17. SPIEGEL-ADOLF, M ; BAIRD, H. W.; COLEMAN, H. S. \& SZIKELY, E. G. Vacuolized blood lymphocytes in the lipidoses and other nervous system diseases with special reference to histochemical studies. In Stanley M. Aronson \& Bruno W. Volk: Cerebral Sphingolipidoses. Academic Press, New York: Cerebral Sphingolipidoses. Academic Press, New York, 1962, p. 129.

18. SUZUK., K. \& CHEN, G. C. - Brain ceramid hexosides in Tay-Sachs disease and generalized gangliosidosis $\left(\mathrm{G}_{\mathrm{M}^{1}}\right.$ gangliosidosis $)$. J. Lipid Res. 8:105, 1967.

19. WALSH, F. B. - Clinical Neurophthalmology. Williams and Wilkins, Baltimore, 1957 , p. 1 .

Clinica Neurológica - Faculdade de Medicina - Universidade de São Paulo Caixa Postal 3461 - São Paulo, SP - Brasil. 